Abstracta Iranica

Revue bibliographique pour le domaine irano-aryen

Volume 40-41 | 2019

Comptes rendus des publications de 2017-2018

\title{
Pierre Lory. La Dignité de l'homme face aux anges, aux animaux et aux djinns
}

\section{Denise Aigle}

\section{OpenEdition}

\section{Journals}

\section{Édition électronique}

URL : http://journals.openedition.org/abstractairanica/51627

DOI : 10.4000/abstractairanica.51627

ISBN : 1961-960X

ISSN : 1961-960X

Éditeur :

CNRS (UMR 7528 Mondes iraniens et indiens), Éditions de l'IFRI

Référence électronique

Denise Aigle, «Pierre Lory. La Dignité de l'homme face aux anges, aux animaux et aux djinns ", Abstracta Iranica [En ligne], Volume 40-41 | 2019, document 2, mis en ligne le 30 décembre 2019, consulté le 16 avril 2021. URL : http://journals.openedition.org/abstractairanica/51627 ; DOI : https://doi.org/ 10.4000/abstractairanica.51627

Ce document a été généré automatiquement le 16 avril 2021.

Tous droits réservés 


\title{
Pierre Lory. La Dignité de l'homme face aux anges, aux animaux et aux djinns
}

\author{
Denise Aigle
}

\section{RÉFÉRENCE}

Pierre Lory. La Dignité de l'homme face aux anges, aux animaux et aux djinns, Paris, Albin Michel, 2018, ISBN 978-2-226-40075-5

1 Le livre de P. Lory est consacré à la place de l'homme dans le cosmos, mais il n'est pas seul car d'autres créatures existent à côté de lui. Il s'agit des anges, des animaux et des djinns qui, au même titre que l'homme, font aussi partie du monde des vivants. Toutes les créatures de Dieu sont mentionnées dans le Coran, les hadiths, les commentaires coraniques, les textes juridiques et les écrits des spirituels musulmans. Pierre Lory se livre ici à une analyse minutieuse de toute cette littérature. Les points de vue des exégètes du Coran et des mystiques sont parfois contradictoires, mais ils peuvent aussi converger dans certains cas. La question principale qui se pose est celle de la nature de ces créatures que sont les anges, les animaux et les djinns par rapport à l'homme.

Dans l'introduction «Qu'est-ce qu'un humain?» (p. 19-39), P. Lory s'interroge sur la nature de l'homme, étant donné que cela détermine le statut des autres êtres qui forment le vivant. La notion de «nature humaine » élaborée dans la pensée grecque, comme l'explique P. Lory, n'a pas d'équivalent dans la tradition musulmane. Les philosophes arabes ont traduit cette notion par les termes tab , ou tabi $i^{\iota}$, d'une racine qui signifie « laisser une trace durable, imprimer " (p. 19-20). Néanmoins, cette définition de la nature reste étrangère à la pensée religieuse qui parle de la disposition accordée à l'homme par Dieu dès sa naissance; elle est désignée par le terme fitra. En d'autres termes, le fait d'être un homme (ou un ange, ou un animal) résulte d'un "statut accordé par Dieu et dépendant de Sa seule volonté » (p. 21). Selon tous les textes 
exégétiques ou spirituels, l'être humain n'est pas le seul à être doté de conscience, d'un esprit (rūh). Le Coran et les hadiths affirment l'existence de quatre catégories de populations qui sont dotées d'esprit. Les «anges» peuplent les cieux mais aussi la terre ; ils sont intelligents, sages et purs. Les « djinns » sont des êtres terrestres, mais qui n'ont pas accès aux régions célestes. Ils sont sexués, peuvent être vertueux, croyants et mécréants. On trouve aussi les " animaux ", ce qui peut paraître surprenant car ils sont souvent rejetés parmi les créatures dépourvues de raisonnement. Ils ne suivraient que leur nature innée, sans soumission à des valeurs morales, sans réflexion personnelle (p. 21-22). P. Lory montre dans son livre que le critère pour déterminer la nature d'un être n'est pas celui de l'infériorité ou de la supériorité. Il s'agit plutôt de «discerner la finalité propre à chaque être» dans le projet divin (p. 23). La notion centrale est l'esprit (rūh) qui confère la vie à l'être humain. Il est aussi le véhicule de son destin post mortem. P. Lory pose la question (p. 24) : "Si le rūḥ confère la vie à l'homme, n'est-ce pas le cas pour le monde animal »? Le texte du Coran affirme de façon assez claire que les animaux sont dotés d'une intelligence réelle qui leur permet de connaître leur Créateur, de le louer et d'accomplir Sa volonté.

L'ouvrage comporte deux grandes parties. La première "Hommes et animaux" (p. 43-155) est sans conteste la plus novatrice du livre de P. Lory. Le seconde « Hommes et anges » (p. 159-230) s'intéresse aux anges et aussi aux djinns. Dans le chapitre (« Les animaux croyants et serviteurs de Dieu ", p. 43-67), à partir d'exemples tirés du Coran, P. Lory explique que les animaux sont les signes de la puissance et de la bienfaisance divines. Ils ont été créés pour l'utilité des hommes, se nourrir, se déplacer, porter des charges, etc. Il est admis dans le texte coranique que les animaux peuvent parler, en particulier les oiseaux. Connaître le langage des oiseaux fait partie de l'héritage de Salomon. C'est un apanage des saints hommes.

Non seulement les animaux peuvent servir d'intermédiaires de la volonté divine, ils sont eux-mêmes destinataires de messages divins. Le Coran fournit un exemple explicite d'une communauté animale, celles des abeilles (sourate 16:68-69): "Ton seigneur révéla aux abeilles: "Prenez des demeures dans les montagnes, les arbres et les treillages [...]. Puis mangez de tous les fruits, suivez les voies de votre Seigneur en toute humilité" ». Les commentateurs donnent des interprétations différentes de ce passage coranique. Selon Maybudī, l'auteur d'un commentaire coranique en persan commencé en 1226, l'abeille est un animal de piété (p. 71-73).

5 Les animaux figurent dans les collections de hadiths relatives à l'eschatologie. Abū 'Abd Allāh Muhamamd al-Qurtubī (m. 1271), un savant et traditionniste malikite, explique qu'il existe des formes multiples de mort. Celle des hommes et des animaux du monde terrestre, celle des djinns et des anges. Les animaux ne sont pas une création séparée des hommes, ils ont un destin commun (p. 87-90). On trouve également des allusions coraniques à la survie des animaux dans l'au-delà. Qushayrī (m. 1072), qui était aussi un exégète, dit que les animaux seront ramenés à la vie et rassemblés le Jour de la Résurrection pour être rétribués de leurs bonnes actions les uns envers les autres (p. 92). Les animaux qui ont joué un rôle sacral, comme le veau d'Abraham, le bélier d'Ismaël, les fourmis et la huppe de Salomon, le chien des Sept Dormants, par exemple, ont une place au paradis. Ils y sont présents pour le plaisir des bienheureux; ils font partie de la récompense qui leur a été promise (p. 98-99).

6 L'A. consacre un chapitre au sort des animaux au regard du droit. Dans les textes juridiques, le serpent et le chien sont rejetés car ils sont considérés être en rapport 
avec les démons (shayāțin) et les hommes pervers. Le serpent est particulièrement réprouvé parce qu'il est en rapport avec les djinns. Le bâton de Moïse est décrit dans les hadiths comme un serpent ou un djinn (p. 107). Le chien fait aussi l'objet de réprobation, mais les jugements, selon leur origine, sont divergents. Dans les traditions prophétiques, le statut de cet animal est ambivalent. Selon un hadith figurant dans le Șahịh de Bukhārī, une prostituée se vit pardonnée parce qu'elle avait abreuvé un chien assoiffé (p. 113). L'impureté du chien est cependant une caractéristique majeure de la norme dans l'islam. L'animal est honni non seulement pour son impureté supposée. Néanmoins les écoles juridiques n'adoptent toutes pas le même point de vue. Les chaféites sont les partisans de l'impureté par nature du chien, tandis que les malékites pensent qu'il est pur (p. 259, n. 20). Cependant, ce point de vue négatif doit être tempéré par les nombreux cas de sainteté canine, dont le cas emblématique est celui du chien des «Compagnons de la Caverne» mentionné dans le Coran au début de la sourate 18 (p. 63-67). On peut également citer le cas du chien de Najm al-Dīn Kubrā rendu saint par son regard et qui devint le dévot du cheikh. P. Lory cite d'autres cas de sainteté canine (p. 152-153). Les animaux apparaissent très fréquemment dans les textes mystiques et la littérature hagiographie. Les maîtres spirituels les considèrent comme des êtres raisonnables (mukallafūn).

7 Au terme de sa recherche, mettant en lumière les points de vue différents des exprimés par les auteurs, selon qu'ils sont exégètes, juristes ou mystiques, l'A. répond à sa question initiale: comment s'articule le destin de l'homme par rapport à celui des animaux, des anges et des djinns. Il souligne qu'il n'existe aucune catégorie de créatures qui jouisse d'une position ontologique intermédiaire. L'islam ne reconnaît pas de "sur-nature ", tous les êtres qui ne sont pas Dieu sont à un niveau d'égalité (p. 232). P. Lory dit que «même le plus grand des wali-s n'est saint que parce que Dieu a fait de lui son ami » (p. 232). Il fait également remarquer qu'aucun des êtres créés n'est doté de natures stables. Il n'existe nulle « nature » humaine ou angélique, mais simplement un «statut » assigné par Dieu (p. 232). Les anges sont crédités d'une très grande pureté d'intention, d'un dévouement et d'une obéissance à l'égard du divin créateur. Cependant, l'exégèse a souligné leurs réticences au moment de la création d'Adam, le cas équivoque d'Iblīs, la transgression d'Hārūt et Mārūt, par exemple (p. 235). La différence apparaît plus claire s'agissant des humains. Dans le Coran le terme « homme » (insān) désigne le plus souvent « les qualités humbles ou pécheresse de cette créature, ou tout le moins des états neutres moralement»(p. 236). C'est la conformation de l'homme à la volonté divine qui le guide vers son vrai destin et le rend véritablement «humain». S'il ne respecte pas la charia, l'homme brouille les différences entre humains et animaux (p. 236).

8 La richesse de ce livre est fondée sur une grande érudition et une analyse minutieuse des sources. Il reste néanmoins très accessible aux non-spécialistes de l'islam. L'ouvrage de P. Lory s'inscrit dans le sillage de ses nombreuses recherches sur la mystique islamique (Voir par exemple, Alchimie et mystique en terre d'Islam, Paris, Verdier, 1989; La Science des lettres en islam, Paris, Dervy, 2004; Le rêve et ses interprétations, Paris, Albin Michel, 2003). 


\section{AUTEURS}

DENISE AIGLE

CNRS, Orient et Méditerranée, Paris 